\title{
PROJETO PEDAGÓGICO DE UM CURSO DE GEOGRAFIA: INTENCIONALIDADES E PROPOSTAS
}

\author{
${ }^{1}$ Raimunda Abou Gebran, ${ }^{2}$ Maria Helena Pereira, ${ }^{2}$ Marcia Carbonera Cavalcante \\ Universidade do Oeste Paulista - UNOESTE, ${ }^{1}$ Mestrado em Educação, Presidente Prudente, SP. ${ }^{2}$ Curso de Geografia, \\ Presidente Prudente, SP. E-mail: ragebran@hotmail.com
}

\section{RESUMO}

O presente artigo refere-se a uma pesquisa que teve por objetivo analisar a formação do professor em um curso de Licenciatura em Geografia de uma instituição de ensino superior privada, buscando compreender as proposições, concepções e ações que norteiam o curso com vistas a uma formação com qualidade. A pesquisa se justificou pela necessidade de reflexão sobre a formação dos docentes e sua posterior atuação, buscando apontar os avanços e as limitações desse processo, e proposições para a sua redimensão. A pesquisa se configurou como uma perspectiva qualitativa e se apoiou em revisão da literatura e análise documental (projeto pedagógico do curso). O trabalho permitiu desvelar o conjunto de elementos que, de forma direta ou indireta, direcionam e definem o processo de formação do licenciado e compreender como esse processo contribui para uma futura atuação docente na educação básica cujas habilidades e competências revelem identidade e a profissionalização docente.

Palavras-chave: Licenciatura em Geografia, formação docente, ação docente

\section{EDUCACIONAL PROJECT OF A GEOGRAPHY COURSE: INTENTIONALITIES AND PROPOSALS}

\begin{abstract}
This article refers to a study that aimed to analyze the formation of the teacher in a Bachelor's Degree in Geography from a private institution of higher education, seeking to understand the propositions, concepts and actions that guide the course with a view to training with quality. The research is justified by the need to reflect on the training of teachers and their subsequent actions, seeking to identify the advances and limitations of this process, and proposals for its resizing. The research was configured as a qualitative perspective and relied on literature review and documentary analysis (pedagogical project of the course). The work allowed to reveal the set of elements that, directly or indirectly, direct and define the degree of the training process and understand how this process contributes to a future educational performance in basic education whose abilities and skills prove identity and professionalization.
\end{abstract}

Keywords: Degree in Geography, teacher training, teaching activities 


\section{INTRODUÇÃO}

A educação no Brasil passa por profundas mudanças, talvez não tantas quanto a sociedade atual exigiria, mas sem dúvida significativas. Nesse contexto, a Geografia, como componente curricular da escola básica, também se modifica, seja por força das políticas públicas, seja por exigências da própria ciência, uma vez que consideramos que a leitura do mundo é fundamental para que todos nós, que vivemos em sociedade, possamos exercitar nossa cidadania.

O professor, como educador, ao trabalhar com o ensino de Geografia tem diante de si uma sociedade extremamente complexa, permeada de desigualdades e contradições o que torna relevante o seu trabalho considerando os problemas sociais que se desencadeiam nesse processo. Nesse sentido o entendimento e a compreensão dessa realidade têm relação direta com a ciência geográfica, ou seja, o ensino da Geografia deve propiciar a leitura e a análise do mundo vivido e percebido pelos sujeitos, enquanto agentes construtores do espaço. Para tanto, é necessário aprender a pensar o espaço e para isso é necessário aprender a ler o espaço.

Assim, o objetivo da pesquisa centrou-se em analisar a formação do professor em um curso de Licenciatura em Geografia de uma instituição de ensino superior privada, buscando compreender as proposições, concepções e ações que norteiam o projeto pedagógico do curso e que propiciam uma formação com qualidade.

A pesquisa foi desenvolvida na perspectiva qualitativa, assumindo caráter analítico interpretativo. Os procedimentos da pesquisa centraram-se na revisão da literatura pertinente ao tema e na análise documental (projeto pedagógico do curso - em especial, a grade curricular e os planos de ensino) que foram analisados de forma articulada ao projeto pedagógico do curso e as Diretrizes Curriculares Nacionais para a Formação de Professores de Geografia.

\section{REFERENCIAL TEÓRICO}

\section{A Formação do Professor em questão}

A formação de professores no Brasil, a partir da constituição dos cursos de Licenciatura na década de 30 do século $X X$, centra-se nos mesmos moldes e revela que nem sempre as propostas desses cursos apontam para processos de formação/habilitação que propiciem a articulação de dimensões teórica e prática, ética, política e social na formação crítica do profissional.

A Lei de Diretrizes e Bases da Educação Nacional (LDB 9493/96) aponta para a necessidade do compromisso com a formação (inicial e continuada) e atuação do professor das diferentes áreas do conhecimento, em todos os níveis de ensino, com vistas a profissionalização e aprimoramento de sua prática docente. No tocante ao ensino de Geografia, já em 1996, os 
Parâmetros Curriculares Nacionais propuseram as habilidades e competências a serem desenvolvidas em Geografia, e indicavam que o docente, em sua atividade profissional, deveria estar habilitado a trabalhar de forma a desenvolver essas competências e habilidades que propiciassem o entendimento das dinâmicas sócioespacias, das dinâmicas do espaço físico, das relações sociedade natureza, numa perspectiva temporal, das diferentes formas de representação, das diferentes contextualizações e relações políticas e sociais, entre outras.

As Diretrizes Curriculares Nacionais para a Formação Inicial de Professores da Educação Básica em cursos de Nível Superior (Resolução CNE/CP 1 de 18 de fevereiro de 2002, com base nos Pareceres 9/2002 e 27/2001) e as Diretrizes Curriculares para os Cursos de Geografia (Parecer CNE/CES 492/2001) apresentam orientações básicas considerando a necessidade de rever os processos de formação; de proporcionar mudanças nesses processos e aprimorar a capacidade acadêmica dos docentes e atualizar os currículos para as novas competências.

Portanto, um dos propósitos básicos da formação universitária consiste em oferecer aos futuros profissionais da educação uma formação adequada, que integre os desenvolvimentos cognitivo, socioafetivo e técnico, isto é, conhecimentos inerentes à profissionalização docente.

Pereira (2000) afirma:

(....) parece ser o papel do professor bem mais complexo do que a simples tarefa de transmitir o conhecimento já produzido. O professor, durante sua formação inicial ou continuada, precisa compreender o próprio processo de construção e produção de conhecimento escolar, entender as diferenças e semelhanças do processo de produção do saber científico e do saber escolar, conhecer as características da cultura escolar, saber a história da ciência e a história do ensino da ciência com que trabalha e em que pontos elas se relacionam. (p. 47).

Nesse sentido, a formação de professores de Geografia deve se pautar pela concepção do profissional crítico-reflexivo, que deve estar aberta a possibilidade de discussão sobre o papel da educação em suas várias dimensões para a construção da sociedade e para a definição do papel da Geografia na formação geral do cidadão. É necessário que o professor esteja aberto para se inteirar das diferentes posições com maturidade intelectual e com o compromisso social para adotar conscientemente uma dela. Na formação inicial nos cursos universitários é necessário que seja garantido aos alunos o direito de conhecer as diferentes concepções sobre a ciência geográfica de participar da reflexão sobre o papel pedagógico da Geografia para que compreendam que a presença da Geografia tenha propósitos políticos e pedagógicos bem definidos e conscientes.

Segundo Kaercher (2002, p. 48), 
Muitas vezes só trocamos os rótulos ou slogans. Mas continuamos a produzir verdades cristalizadas e, o que é pior mantendo a geografia como algo chato e distante do cotidiano dos alunos. Por que isso ocorre? Porque, para haver "geografia critica" (ou uma geografia renovada) não basta mudar os temas ou atualizar nossas aulas. Não se trata de um problema de conteúdo. É preciso haver uma mudança metodológica que altere a relação professor-aluno, relação esta que, via de regra, continua fria, distante e burocrática? Claro que sim. Entretanto mais fundamental ainda é uma "nova" concepção epistemológica de ciência e de geografia. É preciso uma postura renovada de maior diálogo, não só entre professor e aluno, mas com o próprio conhecimento.

As teorias e os métodos de ensino de geografia devem ser elementos constitutivos do próprio conhecimento escolar, levando-se a considerar a educação como uma estratégia básica de formação humana, isto é deve-se privilegiar o aprender a aprender criar, inovar e construir conhecimento. Segundo Lopes (2010, p. 81)

O trabalho do professor ganha relevo porque é dele a tarefa de, no interior de uma comunidade profissional e de uma tradição disciplinar, transformar, por meio de uma ação complexa, o conhecimento científico em conhecimento a ser ensinado. Podemos identificar, neste ângulo de visão, o saber distinto do ofício docente: a capacidade, sempre em contínuo processo de desenvolvimento, de tornar acessível a todos os alunos o conhecimento geográfico, historicamente acumulado pela sociedade humana.

Outro papel importante que tem sido considerado importante na formação do professor é o da construção da identidade profissional e seu papel na formação. Conforme Pimenta (2009) essa identidade se constrói pelo significado que cada professor confere a atividade docente no seu cotidiano com base em seus valores, seu modo de situar-se no mundo, sua história de vida, seus saberes e representações. É essa identidade profissional que ajuda o professor a delinear suas ações, a fazer escolhas, a tomar decisões, posições a definir por determinados comportamentos e estratégias de pensamento no exercício da sua profissão.

Por isso cabe ao professor entender as especificidades inerentes a geografia, mas desconstruir o caráter de fragmentação que a envolve de forma a intervir no processo de ensinoaprendizagem valorizando o entendimento do espaço geográfico como uma ação humana e física. Ressalta-se a relevância que os conteúdos de geografia não sejam trabalhados de maneira fragmentada, mas sim numa perspectiva integradora, haja vista a ciência geográfica ser uma ciência humana.

\section{Análise do Projeto Pedagógico do Curso}


A partir da análise documental do Projeto Pedagógico do Curso, apresentamos as concepções teóricas e pedagógicas que norteiam o projeto pedagógico do Curso; as proposições assumidas para a elaboração do projeto (estrutura curricular e planos de ensino), as ações propostas para o desenvolvimento do curso no que diz respeito à: abordagem dada ao conhecimento geográfico, ao tratamento metodológico (procedimentos e recursos), à abordagem dada à questão da avaliação.

\section{O projeto pedagógico - concepções teóricas e pedagógicas}

O projeto pedagógico do curso de Licenciatura plena em Geografia da universidade pesquisada, apresenta uma reflexão inicial sobre os objetivos e a importância dos estudos em Geografia, apresentando como meta "é caminhar para um processo de ensino e aprendizagem de qualidade que possa integrar todas as dimensões do ser humano." (PPP, 2014, p. 21). O Projeto aponta para o desenvolvimento de um processo de construção e implementação coletiva oportunizando aos sujeitos envolvidos conhecer um conjunto de informações e a partir destas encaminhar para reflexões, proposições e ações com a participação de todos. No tocante à concepção de Geografia assumida na proposta do curso, verifica-se que está em sintonia com as proposições apresentadas nas Diretrizes Curriculares Nacionais.

De acordo com o projeto, optou-se por uma concepção de Geografia que trata os fenômenos como elementos de sustentação para as explicações que podem ser tecidas em torno deles. A maior preocupação é entender a Geografia, buscando o seu significado. (PPP, p. 23).

Esta concepção de curso desenvolve no educando a capacidade de análise crítica e científica de processos que norteiam a sociedade inserindo-o como agente transformador e construtor de conhecimento. Desenvolve a habilidade de analisar questões mundiais, nacionais e locais, utilizando seu potencial teórico e seu comprometimento com seus objetivos relacionados à ciência.

\section{Perfil do Profissional a ser formado}

O projeto apresenta de maneira bastante objetiva e sucinta a caracterização do perfil do profissional formado pelo curso. De acordo com o projeto, o profissional, pelas suas competências e habilidades, estará apto para atuar como professor do Ensino Fundamental e Médio. Também poderá atuar como consultor na elaboração de estudos e relatórios de impacto ambiental, bem como na elaboração, análise, interpretação de mapas e cartas. Além disso, poderá fazer consultoria para empresas em geral e serviços topográficos. Há que se ressaltar, contudo, que 
quando da proposição da estrutura curricular são apontadas várias ações relacionadas ás atividades de pesquisa e extensão que não são abordadas ao se analisar o perfil do profissional.

\section{Estrutura Curricular do Curso}

O projeto aponta que "a distribuição das disciplinas do Curso de Geografia está fundamentada numa lógica de aprofundamento progressivo de questões relativas ao perfil éticopolítico do curso. Trata-se da articulação da teoria geral do homem tanto à prática que se refere à vida social, política, cultural e religiosa, quanto aos fundamentos epistemológicos da Geografia". (op. cit., p. 26). O currículo do Curso de Geografia (2014) está organizado em seis semestres com uma grade que contempla 38 disciplinas, que são consideradas unidades de estudo, compondo um total de 2.880 horas, 400 de estágio supervisionado e 250 horas de Atividades AcadêmicoCientífico-Culturais, totalizando 3.530 horas.

O projeto do Curso apresenta ainda a proposição de se trabalhar com temas transversais que objetivam o aprofundamento de temas relativos à Geografia e, concomitantemente, o aprofundamento de questionamentos relativos ao perfil ético-político do Curso.

Como propostas para o aprimoramento da formação do licenciado o curso tem propiciado ações relevantes à pesquisa científica que se revelam nos projetos de iniciação científica, especialmente em Educação Ambiental, Reciclagem de Materiais, Educação das Relações ÉtnicoRaciais e Ensino de História e Cultura Afro-brasileira e Indígena e em eventos acadêmicos e Científicos organizados pela FACLEPP como Simpósio de Iniciação Científica, Jornada da Educação e Encontro de Ensino, Pesquisa e Extensão (ENEPE),

Para integralização de carga horária, o Projeto Pedagógico contempla algumas disciplinas que o aluno poderá cursar na modalidade semipresencial (50\%), as quais são selecionadas semestralmente no momento da atribuição de aulas. Para tanto são propostas atividades de orientação e treinamento com vistas ao melhor desempenho dos alunos e dos professores. Apesar de estar explicitado no projeto as atividades de pesquisa realizadas pela FACLEPP, como um todo, não são apresentadas as proposições específicas do Curso de Geografia.

\section{- Abordagem dada ao conhecimento geográfico,}

A proposta do curso explicita metas relacionadas à formação do profissional cidadão relacionando-as ao saber (conhecimentos), ao saber fazer (habilidades) e ao saber ser (atitudes). 0 curso prima pelo respeito à diversidade, à qualidade de ensino, ao estímulo à autonomia, à ênfase no aprender a conhecer, a fazer, a ser, a conviver, à participação cooperativa do educando e à 
utilização das novas tecnologias de informação e comunicação. Aponta-se, de forma muito tímida a preparação do licenciado para o exercício profissional da docência, destacando-se o papel e a função social do educador. É confirmado que essa formação deverá ser realizada com sólido domínio de conceitos geográficos articulada com outras áreas de conhecimento.

Ressalte-se, no entanto, que no projeto não são explicitadas as concepções teóricas e metodológicas da área de Geografia assumidas pelo curso e pelos docentes que pudessem permitir a compreensão da abordagem do conteúdo.

\section{- Tratamento metodológico (procedimentos e recursos),}

A concepção de ensino e aprendizagem assumida no projeto está centrada no aluno e nos processos de interação. Aponta-se a necessidade de os alunos serem motivados para aprender a aprender, aprender a investigar e aprender a trabalhar em grupo. Propõe-se que esse processo, coordenado pelos docentes do curso, favoreça aos alunos a integração, a busca autônoma da informação, dando apoio à resolução dos problemas. Apesar da proposição de articulação, o projeto apresenta de forma distinta, aulas teóricas (aulas expositivas) e aulas práticas (de campo) revelando ainda a dicotomia teoria-prática. Da mesma forma, não se explicitam, de forma clara, as concepções de educação e de processo de ensino e de aprendizagem que norteiam as proposições metodológicas, articuladas às concepções da área específica.

Quanto aos recursos a serem utilizados pelos docentes, o projeto indica que a universidade dispõe de equipamentos audiovisuais e laboratórios equipados adequadamente, além de contar com ferramenta virtual AVA (Ambiente Virtual de Aprendizagem) para todas as disciplinas.

\section{- Abordagem dada à questão da avaliação}

No projeto fica claro que a concepção de avaliação assumida é a de avaliação como instrumento e crescimento tanto do docente como do aluno. Nessa visão, o processo de avaliação integra-se ao processo de aprendizagem como um elemento de incentivo e motivação para novos conhecimentos. Os objetivos estabelecidos no plano é que vão orientar sobre "o que avaliar", "de que forma avaliar", "que instrumento ou técnica será utilizada", "como discutir os equívocos e acertos", “qual encaminhamento será dado". Segundo Masetto (2003, p. 156)

A clareza quanto aos objetivos a serem alcançados e como serão avaliados é de fundamental importância para alunos e professor, para lhes oferecer segurança quanto ao comportamento de ambos: o aluno sabendo onde deverá chegar e que passos deverá percorrer para isso; o professor sabendo quais as aprendizagens a serem obtidas pelo aluno e por meio de que referenciais poderá perceber se de fato foram ou não atingidas. 
Na proposta do curso as "avaliações devem ter uma função diagnóstica que proporcione um levantamento da realidade do ensino no que tange à situação dos graduandos quanto às habilidades e conteúdos avaliados" (PPP, 2014, p. 40)

\section{Considerações Finais}

A presente pesquisa se insere em um projeto que tem como objetivo analisar a identidade da formação do professor em cursos de Licenciatura em Geografia. Justificou-se pela necessidade de reflexão sobre a formação dos docentes e sua posterior atuação, buscando apontar os avanços e as limitações desse processo, e proposições para a sua redimensão.

Consideramos que o projeto está bem organizado e estruturado, contemplando as normatizações e orientações estabelecidas pela legislação vigente. Apresenta as indicações básicas para nortear a ação dos gestores, o trabalho docente e os alunos do curso. Contudo, algumas questões merecem atenção quanto à especificidade da área: apresentação do perfil dos alunos do curso; apresentação de forma clara e definida das concepções teórico-metodológicas relacionadas à área específica e ao processo ensino-aprendizagem que poderão melhor direcionar o processo; apresentação de atividades específicas do curso, em especial às relacionadas a estudos do meio; maior direcionamento das atividades de pesquisa e extensão (relacionar com as especificidades do curso); apresentação dos recursos e mídias relacionadas às especificidades do curso (laboratórios, softwares, etc); maior direcionamento das atividades de estágio para a área específica; revisão das ementas e bibliografias das disciplinas oferecidas no curso.

\section{REFERÊNCIAS}

BRASIL. Lei de Diretrizes e Bases da Educação Nacional no 9394, de 20 de dezembro de 1996.

BRASIL. Secretaria de Educação Fundamental. Parâmetros Curriculares Nacionais: introdução aos parâmetros curriculares nacionais. Brasília: MEC/SEF, 1997.

BRASIL. Conselho Nacional de Educação. Conselho Pleno. Resolução CNE/CP 1, de 18/02/02. Institui Diretrizes Curriculares Nacionais para a Formação de Professores da Educação Básica, em nível superior, curso de licenciatura, graduação plena.

BRASIL. Ministério da Educação. Conselho Nacional de Educação. Parecer CNE/CES 492/2001 de 03/04/2001. Diretrizes Curriculares para o Curso de Geografia.

CALLAI, Helena C. A articulação teoria-prática na formação do professor de geografia. In: SILVA, Aida Maria M. et. al. Educação formal e não formal, processos formativos e saberes pedagógicos: desafios para inclusão social. Encontro Nacional de Didática e Prática de Ensino. Recife: ENDIPE, 2006. p. 143- 161. 
. Estudar o lugar para compreender o mundo. In: CASTROGIOVANNI, A. C. (Org.). Ensino de geografia: práticas e textualizações no cotidiano. Porto Alegre: Mediação, 2000.

KAERCHER, Nestor André. A geografia crítica - alguns obstáculos e questões a enfrentar no ensinoaprendizagem de geografia. (45-65) IN: Boletim Gaúcho de Geografia, vol 28, no1, Porto Alegre: AGB, 2002.

MASETTO, M.T. Competência pedagógica do professor universitário. São Paulo: Summus, 2003.

PEREIRA, Júlio Emílio Diniz. Formação de professores: pesquisas, representações e poder. Belo Horizonte: Autêntica, 2000.

PIMENTA, Selma G. (Org). Saberes pedagógicos e atividade docente. 7. ed. São Paulo: Cortez Editora, 2009. 